\title{
Resveratrol can both enhance and relax adrenergic contractions of the rat tail artery
}

\author{
Sayra M. Stom, Laura E. Phelps, and Jacob D. Peuler \\ Pharmacology Department, Midwestern University, Downers Grove, IL 60515, USA
}

\begin{abstract}
Our aims were to determine 1) if resveratrol's vasorelaxant action is greater in the distal (resistance) versus proximal (conductance) portion of the rat tail artery, and 2 ) if it can be blocked by agents known to block different potassium $(\mathrm{K})$ channels in arterial smooth muscle. We found that its half-maximally effective concentration values were essentially identical ( $25 \pm 3$ versus $27 \pm 3 \mu \mathrm{M}$ ) for relaxing adrenergically-precontracted rings prepared from distal versus proximal tissues. This does not confirm a previous report of greater relaxation in resistance versus conductance arteries. We also found that its relaxation could not be blocked by any of seven different $\mathrm{K}$ channel blockers. However, we uncovered a novel unanticipated action not yet reported. In half our arterial ring preparations, resveratrol transiently enhanced adrenergically-induced precontractions beginning well before its sustained relaxant effect became apparent. This action provides the first reasonable explanation for previously unexplained increases in arterial pressures observed during acute intravenous administration of resveratrol to animal models of traumatic ischemic tissue injury, in which hypotension is often present and in need of correction. Also unanticipated, this same transient enhancement of adrenergic contraction was notably inhibited by some of the same $\mathrm{K}$ channel blockers (particularly tetraethylammonium and glibenclamide) that failed to influence its relaxant effect. Although we do not rule out smooth muscle as a possible site for such a paradoxical finding, we suspect resveratrol could also be acting on K-selective mechano-sensitive ion channels located in the endothelium where they may participate in release of contracting factors.
\end{abstract}

Key words: arterial pressure and smooth muscle, potassium channels, resistance and conductance arteries, endothelium

\section{Introduction}

The health benefits of resveratrol as evidenced by both preclinical experiments and clinical trials in humans suggest that this natural polyphenol, commonly known for its powerful antioxidant action, may play an important role in preventing a variety of diseases (1-11). In hypertensive rat models, oral resveratrol has been

Corresponding author: Jacob D. Peuler, Midwestern University Department of Pharmacology, $55531^{\text {st }}$ Street, Downers Grove, IL 60515, USA

Phone: 630-515-6068 Fax: 630-515-6259 e-mail: jpeule@midwestern.edu

(C)2016 The Japan Society of Smooth Muscle Research 
shown to improve cardiovascular function by chronically lowering arterial pressure $(4,5,7,9,11)$ and preventing cardiac hypertrophy $(5,7)$. In human clinical trials, resveratrol has not only been shown to reduce arterial pressure chronically but also induce metabolic changes such as improving glycemic control in patients with type 2 diabetes mellitus (2) or obesity (10). Given its ability to lower arterial pressure, it is not surprising that several published studies have consistently shown that resveratrol can directly relax precontracted smooth muscle in various arteries in vitro (12-16). One vessel not yet studied is the long ventral tail artery of the laboratory rat, despite being widely recognized as a convenient, inexpensive and yet valid model for many other arteries throughout the body (17-19). Our lab has successfully used the rat tail artery as a model for studying mechanisms of direct relaxant effects of other agents also known for lowering arterial pressure chronically (20-23). Therefore, the purpose of our studies was to further investigate resveratrol's arterial relaxant effect using the rat tail artery model. Our specific aims (studies) were as follows. Detailed rationale for these aims (studies) are presented in the Discussion section under Specific aim related findings.

1. Determine if (hypothesis \#1) the ability of resveratrol to relax arterial smooth muscle in vitro is significantly greater in the distal (resistance) portion of the rat tail artery than in the proximal (conductance) portion of the same vessel.

2. Determine if (hypothesis \#2) resveratrol's relaxation of rat tail arterial tissue in vitro can be antagonized by any of the following: tetraethylammonium, iberiotoxin, apamin, glibenclamide, barium, margatoxin and/or 4-aminopyridine; agents known to block different subpopulations of potassium channels in arterial smooth muscle.

\section{Methods}

\section{Isolation and preparation of arterial contractile tissue rings}

For all experiments described below under Studies 1 and 2 adult male Sprague-Dawley rats were euthanized (as approved by the Institutional Animal Care and Use committee at Midwestern University) for removal of the ventral tail artery (Fig. 1) and its storage as previously recommended (24). We employed this vessel because of its wide-spread recognition as a convenient, inexpensive yet valid model for other arteries (17-19). As recently studied and reviewed by Souza et al. (19), while its most proximal segment resembles large conductance (conduit) arteries its most distal segment is very similar functionally and structurally to the many resistance vessels throughout the body (small arteries and arterioles) that contribute to the regulation of arterial pressure. Souza concluded that the distal segment of the rat tail artery "is a suitable resistance vessel preparation" (19). Over 25 years ago, Rajanayagam and Medgett concluded similarly after comparing the distal to the proximal (18) and to sympathetic vasoconstrictor tone in the human forearm (17). Accordingly, proximal and distal segments of each vessel were isolated (Fig. 1), cleaned and carefully sectioned into multiple 3-mm cylindrical rings using a bound set of evenly-spaced scalpel blades as we have successfully employed previously (20-23). As described in Fig. 1, a maximum of eight rings were selected at random from the middle portion of each segment for experimental treatments during each experimental period. Each ring was mounted between two tungsten wire stirrups, which in our experience $(20-23,25)$ are strong enough not to bend during ring contractions yet thin enough not to damage the inner endothelial cell layer [presence of intact endothelium was confirmed by relaxation responses to acetylcholine in a representative number of precontracted rings in preliminary and follow-up experiments]. Each ring was then suspended in a $40 \mathrm{ml}$ tissue bath and allowed to equilibrate for several minutes before experimentation at a passive loading (resting) tension of $1,500 \mathrm{mg}$ in standard physiological (Krebs) buffer which was warmed to $37^{\circ} \mathrm{C}$ and gassed to $\mathrm{pH} 7.4$ with regulated delivery 


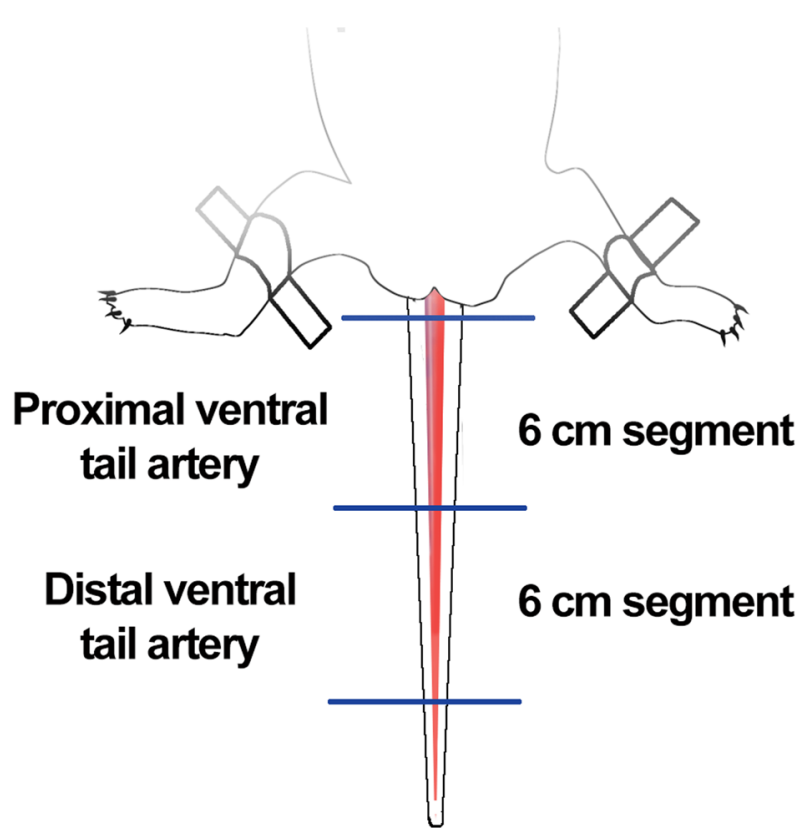

Fig. 1. Proximal and distal segments of the ventral tail artery of the adult male rat. After isolation and storage using cold buffer, eight $3-\mathrm{mm}$ rings were cut for each experiment from the middle portion of each $6 \mathrm{~cm}(60 \mathrm{~mm})$ segment and used as described in Methods. Unused end portions of each segment were discarded.

of $\mathrm{O}_{2} / \mathrm{CO}_{2}$. All tensions for these tissues were recorded (in mg units) with the aid of force transducers connected to an 8-channel Grass chart recorder. To observe resveratrol's relaxant effects on contractile tensions of arterial tissues in vitro, it was obviously necessary to first precontract them with a known contractile agonist. We chose an alpha adrenergic receptor agonist because of the widely recognized importance of adrenergic vasoconstrictor support of arterial pressure in vivo. We chose the smooth muscle selective alpha-1 agonist phenylephrine (PE) for that purpose because 1) it has already been repeatedly employed successfully by other resveratrol investigators in other arteries $(12,15)$ and 2$)$ as we have discussed previously $(25)$ it produces more sustained precontractions than other agonists previously used in other resveratrol studies (e.g. high potassium buffer or the nonselective adrenergic agonist norepinephrine) $(13,16)$.

Study 1 (specific aim 1): determine if (hypothesis \#1) the ability of resveratrol to relax arterial smooth muscle in vitro is significantly greater in the distal (resistance) portion of the rat tail artery than in the proximal (conductance) portion of the same vessel. We contracted individual tail artery rings with PE at $0.5 \mu \mathrm{M}$, which in our previous experience closely approximates its half-maximally effective concentration $\left(\mathrm{EC}_{50}\right)$ in the whole tail artery (20). Prior to the administration of resveratrol, several minutes of PE contractility were recorded to allow it to stabilize. We tested eight rings simultaneously each with a different concentration of resveratrol ranging between $0-80 \mu \mathrm{M}$; i.e. a control (given DMSO as vehicle at a final concentration of $0.05 \%$ ) and several concentrations similar to those tested previously by Naderali et al. (13) in a previous comparison of resistance and conductance arteries but from mesenteric and uterine circulations as described in detail the Discussion section. Thus, concentrations of $0,2,5,10,20,30,40$ and $80 \mu \mathrm{M}$ were used on both proximal and distal portions of each rat tail artery. We recorded contractile tension data from all rings for $2.5 \mathrm{~h}$ following administration of resveratrol since this amount of time was often needed for complete relaxations to occur, particularly at low concentrations if unanticipated transient increases in contractile tensions occurred immediately after its administration. These often required considerable time to disappear (Fig. 2B). Determination and display 
of magnitude and duration of these transient increases are presented in Figs. 3 and 4. Final relaxation effects of resveratrol were calculated as percent decrease from contractile tensions recorded immediately prior to its administration. We repeated the study eight times for rings from each tail artery segment, alternating the order in which we tested the proximal and distal segments from the same vessel from one experimental period of time to the next. Naderali et al. (13) found that $n=7-8$ rings per experimental group was sufficient to detect a statistically significant greater relaxant effect of resveratrol in their mesenteric resistance arteries versus uterine conductance arteries.

Study 2 (specific aim 2): determine if (hypothesis \#2) resveratrol's relaxation of rat tail arterial tissue in vitro can be antagonized by any of the following: tetraethylammonium, iberiotoxin, apamin, glibenclamide, barium, margatoxin and/or 4-aminopyridine; agents known to block different subpopulations of potassium channels in arterial smooth muscle. In each experiment of this study, prior to contracting eight tail artery rings with PE, we individually exposed them to seven different known potassium $(\mathrm{K})$ channel blockers (plus one control ring with no blocker) and allowed time for any baseline changes in resting tension to stabilize (approximately $20 \mathrm{~min}$ ). The seven $\mathrm{K}$ channel blockers (and concentrations) we employed in this study were as follows: 1) tetraethylammonium (TEA) at $1 \mathrm{mM}$ to inhibit all large- and intermediate-conductance calcium-activated $\mathrm{K}$ channels $\left(\mathrm{K}_{\mathrm{Ca}}\right)$, 2) iberiotoxin (Iberio) at $50 \mathrm{nM}$ to inhibit only large-conductance $\mathrm{K}_{\mathrm{Ca}}, 3$ ) apamin at 100 $\mathrm{nM}$ to inhibit only small-conductance $\mathrm{K}_{\mathrm{Ca}}, 4$ ) glibenclamide (Glib) at $10 \mu \mathrm{M}$ to inhibit only ATP-sensitive $\mathrm{K}$ channels ( $\left.\mathrm{K}_{\text {ATP }}\right), 5$ ) barium at $10 \mu \mathrm{M}$ to inhibit only inward rectifier $\mathrm{K}$ channels $\left.\left(\mathrm{K}_{\mathrm{IR}}\right), 6\right)$ margatoxin (Marga) at $10 \mathrm{nM}$ to inhibit only subtype 1 of all voltage-dependent $\mathrm{K}$ channels $\left(\mathrm{K}_{\mathrm{VI}}\right)$, and 7) 4-aminopyridine (4AP) at $1 \mathrm{mM}$ to inhibit all voltage-dependent $\mathrm{K}$ channels $\left(\mathrm{K}_{\mathrm{V}}\right)$. These selections were based on the following three sources: 1) all previous studies of the role of K channels in resveratrol's relaxation of other arteries $(12,14-16)$ as presented in Discussion, 2) extensive reviews of all major subpopulations of $\mathrm{K}$ channels in arterial vascular smooth muscle $(26,27)$, and 3) successful efforts by ourselves and others to assess $\mathrm{K}$ channel involvement in relaxant actions of other substances specifically in the rat tail artery $(20,21,28)$. The control ring in each experiment was given $\mathrm{K}$ channel blocker vehicles (water and DMSO) administered in volumes already known to exert no effects of their own on contractile tensions. Following administration of PE at $0.5 \mu \mathrm{M}$ as in Study 1, we allowed time for PE contractions to stabilize before administering resveratrol ( $26 \mu \mathrm{M}$; the overall mean of its $\mathrm{EC}_{50}$ values, 25 and $27 \mu \mathrm{M}$, calculated from Study 1), and then we recorded contractile tension data for at least two hours after resveratrol (which similar to Study 1 was needed to allow full relaxations to occur). We repeated this study eight times for each tail artery segment because the average of all $n$ values previously needed by others to detect $\mathrm{K}$ channel blocker effects on resveratrol relaxation in other vessels $(12,14-16)$ was 7.5 (range of $n=3-17$ ). As in Study 1 we alternated the order in which we tested the proximal and distal tissue segments from the same vessel. As in Study 1, we recorded magnitude and duration of any transient increases in contractile tensions that occurred in response to resveratrol prior to its relaxant effects. Final relaxant effects of resveratrol were calculated as percent decrease from contractile tensions recorded immediately prior to resveratrol's administration, as in Study 1.

\section{Analysis of data}

Analysis of data involved assigning numerical values to (and/or calculating numerical values from) chart recordings of the various tissue contractile tension parameters (as defined in the above studies). Except for calculated $\mathrm{EC}_{50}$ values, all other numerical values were entered into computerized spread sheets for statistical evaluation by way of appropriate analysis-of-variance (ANOVA) followed by multiple mean comparison tests (Dunnett's and Tukey's; if justified by ANOVA) for detection of statistically significant effects of the different 

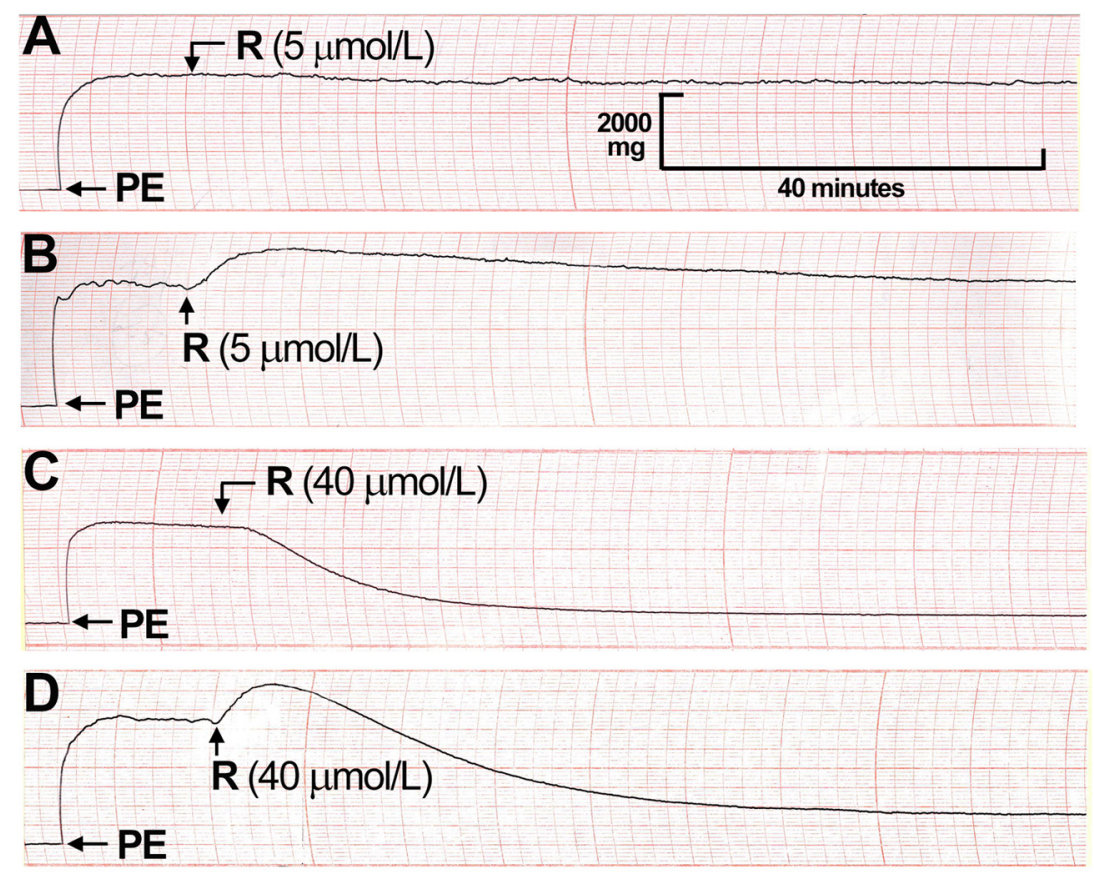

Fig. 2. Representative chart recordings of effects of resveratrol (R) on phenylephrine (PE)-induced contractions of four different distal rat tail arterial rings. A: lack of effect by $5 \mu \mathrm{M}$. B: transient increase by $5 \mu \mathrm{M}$. C: sustained decrease by $40 \mu \mathrm{M}$. D: transient increase followed by sustained decrease by $40 \mu \mathrm{M}$. Each $\mathrm{PE}=0.5 \mu \mathrm{M}$. Similar effects were observed with proximal arterial rings.

experimental conditions (e.g. distal versus proximal arterial tissue segments). $\mathrm{EC}_{50}$ values were evaluated with unpaired $t$-tests. All data were presented in the form of mean + - S.E.M. with a $\mathrm{p}$ value for significance equal to or less than 0.05 .

\section{Results}

Study 1 (specific aim 1): determine if (hypothesis \#1) the ability of resveratrol to relax arterial smooth muscle in vitro is significantly greater in the distal (resistance) portion of the rat tail artery than in the proximal (conductance) portion of the same vessel. The results from this study can be found in Figs. 2-5. In Figs. 3-5, the measures expressed along the y-axis were subjected to 2-factor ANOVA in which factor 1 was resveratrol at varying concentrations $(0,2,5,10,20,30,40$ and $80 \mu \mathrm{M})$ and factor 2 was the type of arterial segment (distal vs. proximal).

Figure 2 shows representative chart recordings of effects of resveratrol on phenylephrine (PE)-induced contractions. As expected, there were no significant differences in the ability of rings prepared from the different arterial segments (distal or proximal) to contract in response to PE prior to addition of the different resveratrol test concentrations (data not shown). The overall magnitude of such PE-induced contraction was 3,760 $\pm 98 \mathrm{mg}$ for all distal rings ( $n=64$ total) and 3,614 $\pm 94 \mathrm{mg}$ for all proximal rings ( $n=64$ total).

Figure 3 shows an unanticipated finding of transient resveratrol-induced increases in PE-induced contractions observed before its anticipated relaxant effects. These transient increases began immediately (Fig. 2: B and D) and reached their maximum (peak values) 5-15 min after the addition of resveratrol. It is the magnitude of these peak values that is shown in Fig. 3. This finding was observed in over half (62\%) of the total number of 


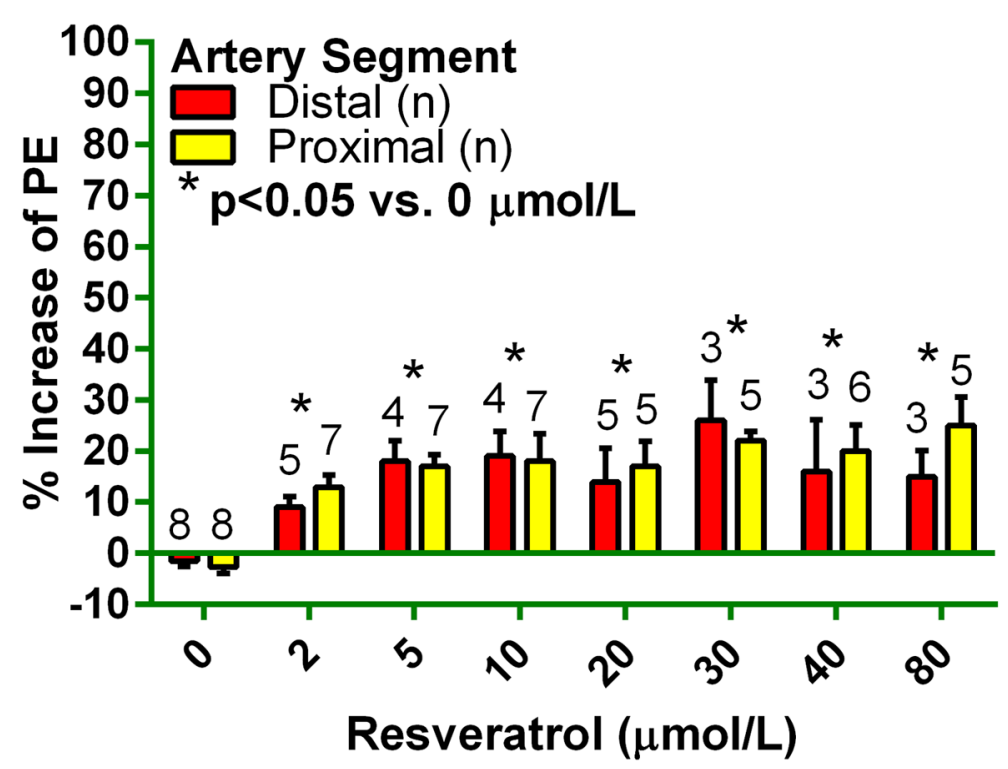

Fig. 3. Magnitude of transient resveratrol-induced increases in PE-induced contractions observed (at their maximum) 5-15 min after addition of resveratrol. None were observed at $0 \mu \mathrm{M}$. The slight decreases shown at $0 \mu \mathrm{M}$ (no resveratrol) were recorded 10 min after addition of vehicle (DMSO) to control tissues. ${ }^{*} P<0.05$ vs. $0 \mu \mathrm{M}$ represents statistically significant effects (as determined by multiple mean comparisons) only when distal and proximal data are combined, not when analyzed separately. Not indicated is a statistically significant main factor effect for resveratrol from the 2-factor ANOVA.

tissues subjected to resveratrol and regardless of its test concentration. This did not occur in any of the control tissues given resveratrol's vehicle (DMSO) only. Thus, the magnitude of these increases at all test concentrations was found to be significantly different from the data shown for control tissues in Fig. 3. They were not significantly different from each other although they appeared to be slightly smaller at $2 \mu \mathrm{M}$ compared to all higher levels. Also, there was no significant difference in the magnitude of these transient increases between arterial segment types (distal vs. proximal). Finally, while the time to peak values for the magnitude of these increases all occurred within the brief period of 5-15 min after addition of resveratrol, their full durations in time lasted much longer. They ranged from nearly $2 \mathrm{~h}$ at $5 \mu \mathrm{M}$ resveratrol down to slightly under $30 \mathrm{~min}$ at 80 $\mu \mathrm{M}$ (Fig. 4), thus decreasing in time as relaxation occurred with increasing concentrations. Also, there were no significant differences in these durations between arterial segment types (distal vs. proximal).

In Fig. 5, we see sustained decreases in PE-induced contractions observed $2.5 \mathrm{~h}$ after addition of resveratrol to all tissues combined; i.e. those which did not and those which did show the transient increases in PE contractions much earlier (as shown in Fig. 3). As expected, there was a graded relaxant effect as resveratrol concentrations increased (Fig. 5). The relaxant effect of resveratrol was statistically significant at concentrations of $10 \mu \mathrm{M}$ and higher compared to the control tissues given resveratrol's vehicle only. Figure 5 also depicts a significant difference in the type of arterial segment; namely, distal segments showed slightly greater relaxation than proximal segments overall. However, although this difference was only statistically significant as an overall effect and not at each level of resveratrol individually (including $0 \mu \mathrm{M}$ ), it was nonetheless noticeable in its absence as well as in its presence. Thus, this difference might be due to simply a slightly greater rate of gradual decay of the PE contractions by themselves in distal compared to proximal segments over the long length of time $(2.5 \mathrm{~h})$ that $\mathrm{PE}$ remained present. In addition, resveratrol's half-maximally effective concentration values $\left(\mathrm{EC}_{50}\right.$ values) 


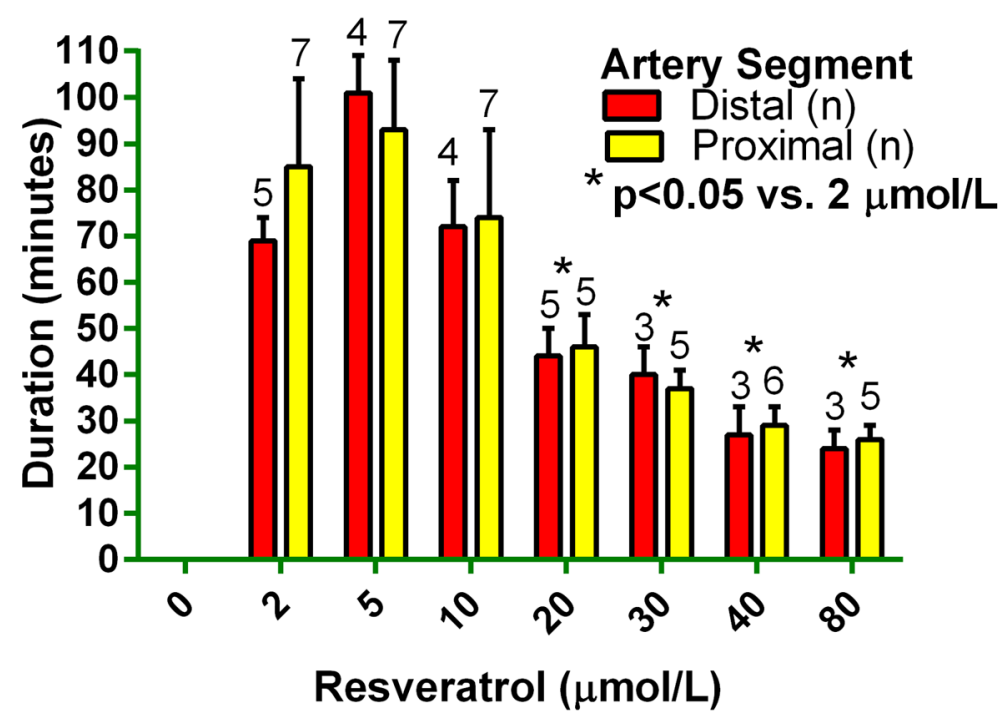

Fig. 4. Duration of transient resveratrol-induced increases in PE-contractions observed after addition of resveratrol. None were observed at $0 \mu \mathrm{M}$. Durations were calculated as minutes between immediately when the PE-induced contractions began to rise after addition of resveratrol and the time when they returned to values observed immediately before its addition. ${ }^{*} P<0.05$ vs. $2 \mu \mathrm{M}$ represents statistically significant effects (as determined by multiple mean comparisons) only when distal and proximal data are combined, not when analyzed separately. Not indicated is a statistically significant main factor effect for resveratrol from the 2-factor ANOVA.

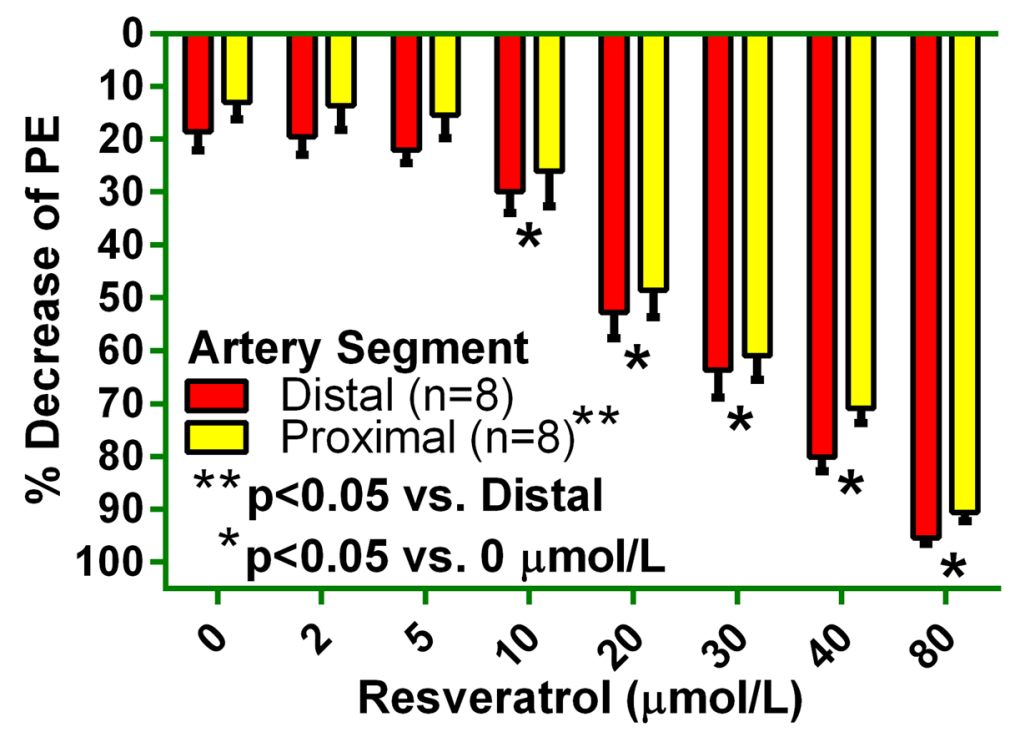

Fig. 5. Magnitude of sustained resveratrol-induced decreases in PE-induced contractions observed $2.5 \mathrm{~h}$ after addition of resveratrol. $* * P<0.05$ vs. Distal only represents a statistically significant main factor effect for artery segment (proximal vs. distal). Multiple mean comparisons did not show statistically significant differences between proximal and distal segments at each individual concentration of resveratrol. $* P<0.05$ vs. $0 \mu \mathrm{M}$ represents statistically significant effects (as determined by multiple mean comparisons) not only when distal and proximal data were combined but also when analyzed separately. Not indicated is a statistically significant main factor effect for resveratrol from the 2-factor ANOVA. 


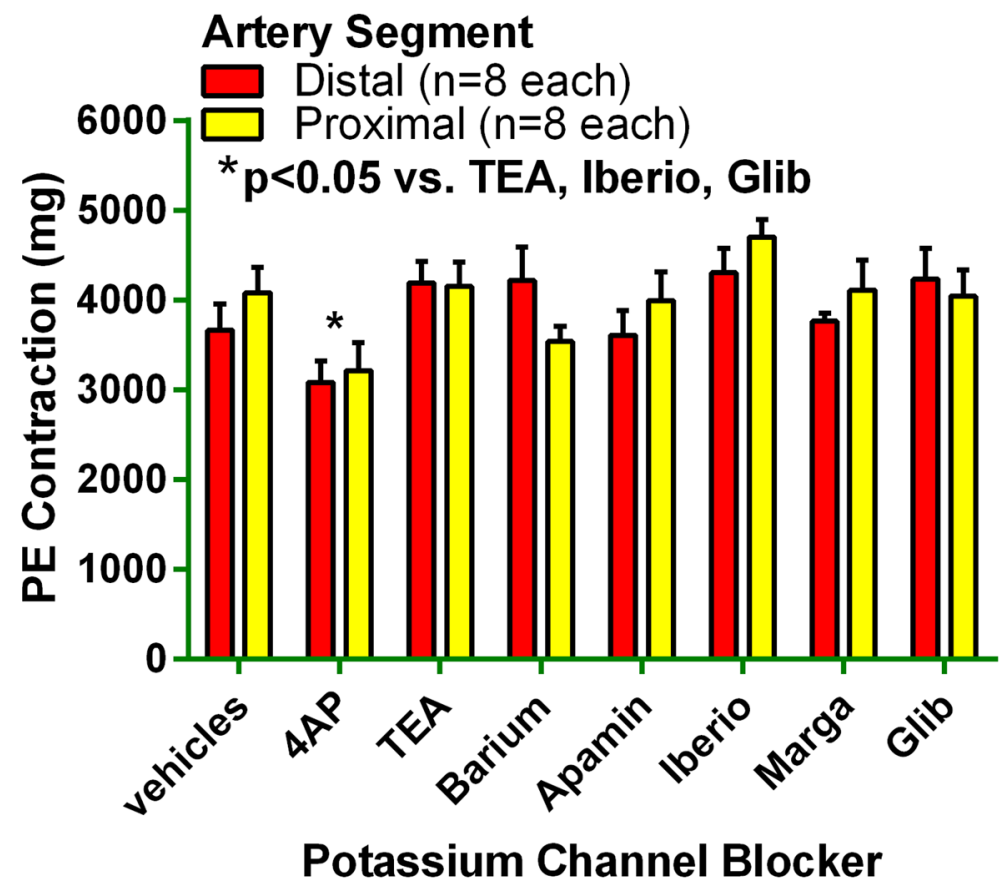

Fig. 6. Effects of potassium channel blockers on the magnitude of phenylephrine (PE)induced contractions observed prior to addition of resveratrol $(26 \mu \mathrm{M})[\mathrm{PE}=0.5$ $\mu \mathrm{mol} / \mathrm{L}] . * P<0.05$ vs. TEA, Iberio, Glib represents statistically significant effects (as determined by multiple mean comparisons) not only when distal and proximal data were combined but also, for Iberio, when analyzed separately. Not indicated is a statistically significant main factor effect for potassium channel blockers from the 2-factor ANOVA.

for distal vs. proximal segments were essentially the same ( $25 \pm 3$ vs. $27 \pm 3 \mu \mathrm{M})$ and those values could only be calculated in the absence of data from the control tissues (tissues not given resveratrol). Thus, taken together these results do not convincingly indicate a greater relaxant action of resveratrol in distal vs. proximal tissue.

Study 2 (specific aim 2): determine if (hypothesis \#2) resveratrol's relaxation of rat tail arterial tissue in vitro can be antagonized by any of the following: tetraethylammonium, iberiotoxin, apamin, glibenclamide, barium, margatoxin and/or 4-aminopyridine; agents known to block different subpopulations of potassium channels in arterial smooth muscle. The results from this study can be found in Figs. 6, 7, 8 and 9. In these Figures, the measures expressed along the y-axis were subjected to 2-factor ANOVA in which factor 1 was K channel blockers (TEA, iberiotoxin, apamin, glibenclamide, barium, margatoxin, 4AP, and vehicles) and factor 2 was the type of arterial segment (distal vs. proximal).

In Fig. 6, we see the effects of potassium (K) channel blockers on phenylephrine(PE)-induced contractions observed well over 20 min after they were administered, just prior to addition of resveratrol (here at a value of $26 \mu \mathrm{M}$ to all, near its $\mathrm{EC}_{50}$ values from Study 1). While none of the $\mathrm{K}$ channel blockers produced significant effects when compared to controls (vehicles), 4AP was found to significantly inhibit PE-induced contractions but only when compared to TEA, iberiotoxin, and glibenclamide. Also, there were no effects of any $\mathrm{K}$ channel blockers on resting tensions observed prior to the addition of PE.

In Fig. 7, we see the effects of potassium $(\mathrm{K})$ channel blockers on the magnitude of the unanticipated transient increases in PE-induced contractions observed (at their maximum) 6-12 min after addition of resveratrol (which was $26 \mu \mathrm{M}$ in all tissues including controls given only the vehicles used for the $\mathrm{K}$ channel blockers). Similar to results found in Fig. 3 of Study 1, these transient increases were only observed in about half the total 


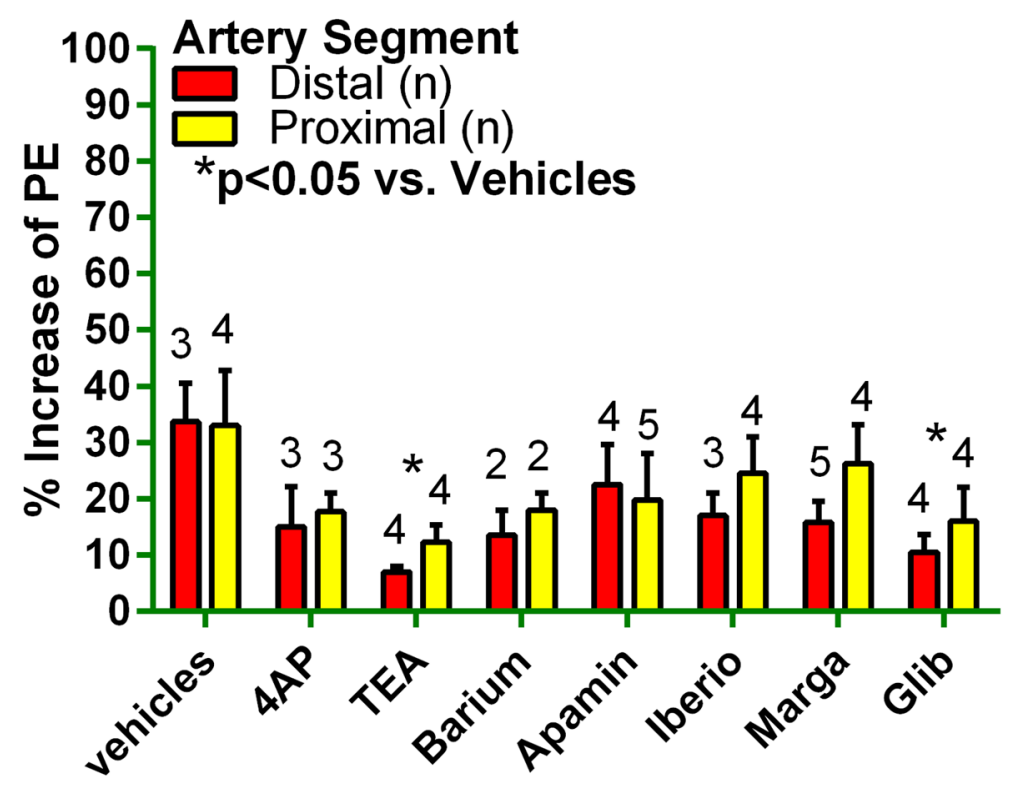

\section{Potassium Channel Blocker}

Fig. 7. Effects of potassium channel blockers on the magnitude of transient resveratrolinduced increases in PE-induced contractions observed (at their maximum) 6-12 min after addition of resveratrol $(26 \mu \mathrm{mol} / \mathrm{L}) . * P<0.05$ vs. Vehicles represents statistically significant effects (as determined by multiple mean comparisons) only when the distal and proximal data are combined, not when analyzed separately. Not indicated is a statistically significant main factor effect for potassium channel blockers from the 2-factor ANOVA.

number of tissues exposed to resveratrol. Most importantly, the $\mathrm{K}$ channel blockers in general, and TEA and glibenclamide in particular, inhibited these increases. Also similar to Fig. 3, there was no significant difference in the magnitude of these transient increases between arterial segment types (distal vs. proximal). Results identical to Fig. 7 were observed in Fig. 8 but for effects of K channel blockers on the durations of the transient increases.

In Fig. 9, we see effects of potassium (K) channel blockers on sustained decreases in PE-induced contractions observed $2 \mathrm{~h}$ after addition of the $26 \mu \mathrm{M}$ resveratrol to all tissues combined; i.e. those which did not and those which did show the transient increases in PE contractions much earlier (as shown in Fig. 7). The graph depicts about $50-60 \%$ relaxation by resveratrol overall and, most importantly, no statistically significant effects of any of the seven K channel blockers tested. Similar to Fig. 5 of Study 1, a small but significant difference was found between arterial segments; again, the distal segments relaxed more than proximal segments. This effect was only significant overall, not at the level of each individual $\mathrm{K}$ channel blocker (or vehicles) separately. As in Fig. 5, it may be due to simply a slightly greater rate of gradual decay of PE-induced contractility by itself in distal vs. proximal segments over the considerable length of time $(2 \mathrm{~h})$ that PE remained present. Finally, the failure of $\mathrm{K}$ channel blockers to alter resveratrol's relaxant effect $2 \mathrm{~h}$ after its administration, as seen in Fig. 9 for all tissues combined, was also observed much earlier (at 6-12 min after) in those particular tissues which did not show the transient increases in PE contractions as seen in Fig. 7. As expected, resveratrol's ability to decrease PE-induced contractions in only those particular rings at that early time was small, 10 $\pm 4 \%$ for $n=5$ distal rings and $8 \pm 2 \%$ for $n=4$ proximal rings. Most importantly, none of the $\mathrm{K}$ channel blockers administered in parallel to the rest of those rings were able to influence those early, small resveratrol-related relaxations (data not shown). 


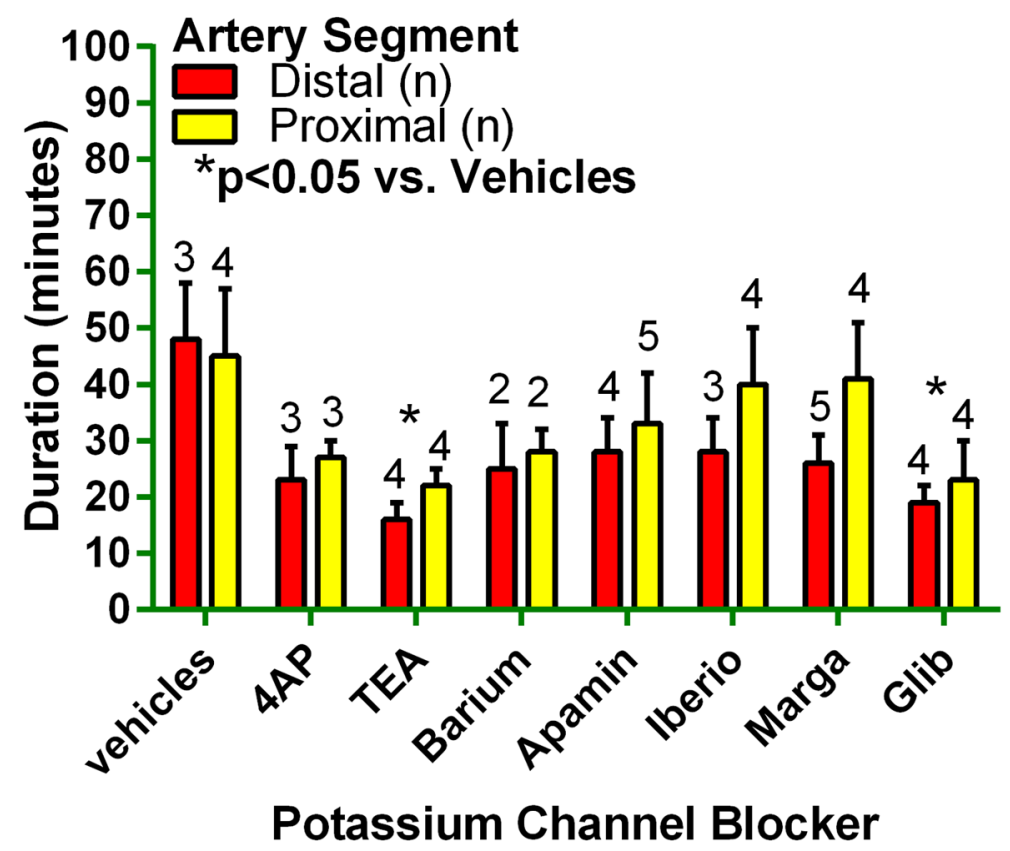

Fig. 8. Effects of potassium channel blockers on duration of transient resveratrol-induced increases in PE-induced contractions observed after addition of resveratrol $(26 \mu \mathrm{M})$. Durations were calculated as minutes between immediately when the PE-induced contractions began to rise after addition of resveratrol and the time when they returned to values observed immediately before its addition. ${ }^{*} P<0.05$ vs. Vehicles represents statistically significant effects (as determined by multiple mean comparisons) only when the distal and proximal data are combined, not when analyzed separately. Not indicated is a statistically significant main factor effect for potassium channel blockers from the 2-factor ANOVA.

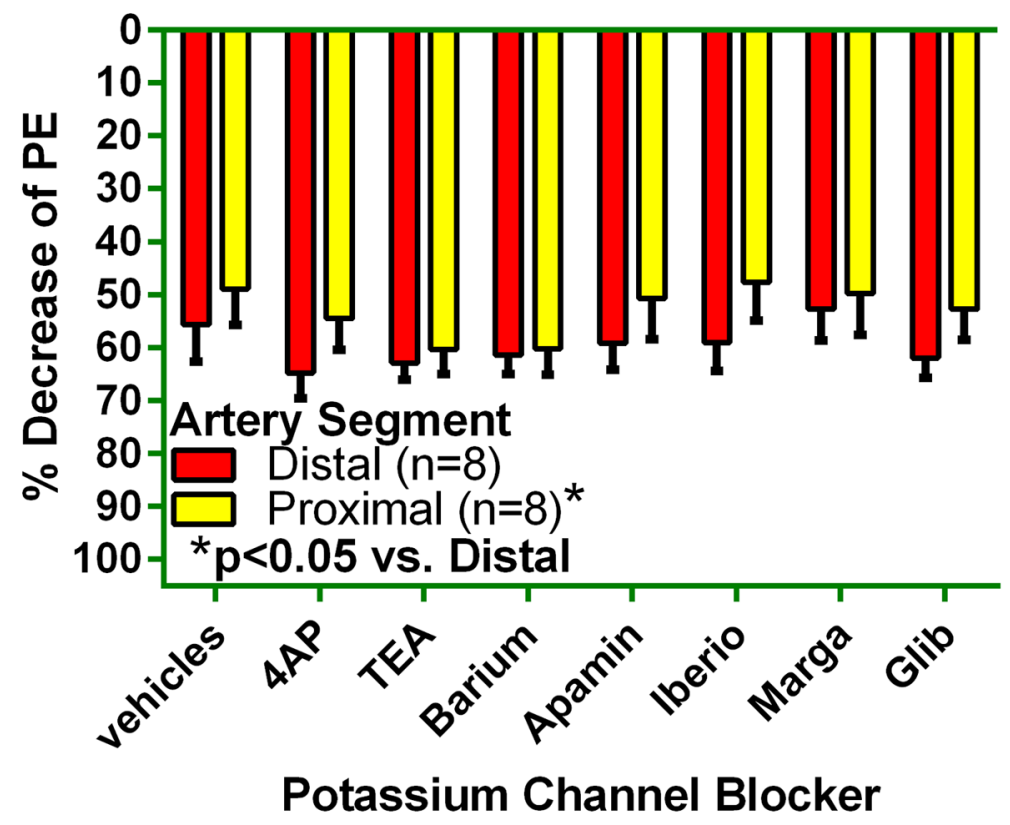

Fig. 9. Effects of potassium channel blockers on the magnitude of sustained resveratrol-induced decreases in PE-induced contractions observed $2 \mathrm{~h}$ after addition of resveratrol $(26 \mu \mathrm{M})$. $* P<0.05$ vs. Distal only represents a statistically significant main factor effect for artery segment (proximal vs. distal). Multiple mean comparisons did not show statistically significant differences between proximal and distal segments at the level of each individual potassium channel blocker. 


\section{Discussion}

\section{Specific aim related findings}

For our first specific aim, we sought to determine if (hypothesis \#1) the ability of resveratrol to relax arterial smooth muscle in vitro is significantly greater in the distal (resistance) portion of the rat tail artery than in the proximal (conductance) portion of the same vessel. Before our results, resveratrol was already known to relax other resistance and conductance arteries in vitro (12-16) but only one laboratory had tested for a difference in that effect. Naderali et al. found that resveratrol's relaxation effect was more potent in mesenteric resistance arteries (second order branches of the main mesenteric artery) than in uterine conductance arteries (segments of the main uterine artery itself) isolated from female guinea-pigs and tested in parallel under the same conditions (13). This was an important finding to confirm in other vessels because 1) resistance blood vessels play a larger role in regulating arterial pressure than conductance vessels (29) and 2) resveratrol's ability to reduce arterial pressure over the long term when taken orally is not yet fully understood. Also, Naderali et al. produced their results by testing different arteries isolated from different organs. In our study, we tested separate segments of the same artery isolated from the same organ. Proximal and distal segments of the long ventral tail artery of the rat have been shown to exhibit both structural and functional characteristics typical of most conductance and resistance arteries in the body (17-19).

If our results had supported our hypothesis that resveratrol's relaxant effect is greater in the more distal resistance segment of the rat tail artery than the proximal conductance segment of the same vessel, we would have next examined what mechanism was responsible for that difference. If Aim \#2 (see below) did not provide the answer to this question, we would have considered the role of arterial endothelium in future studies by repeating the Aim \#1 experiment but with the endothelium deliberately removed. Mechanisms of endothelialdependent dilation are different in resistance versus conductance arteries $(19,30,31)$. Luksha et al. (30) and Woodman et al. (31) both established that the nitric oxide (NO) released by endothelium has a greater role in dilation of conductance arteries while endothelium-derived hyperpolarizing factor (EDHF) has a greater role in endothelium-dependent dilation of resistance arteries. The same difference occurs in the rat tail artery (19). Conceivably, resveratrol might have been acting to enhance that difference. But our results did not convincingly support our hypothesis for this specific aim. Thus, we suspect that resveratrol's relaxant effect is not greater in resistance versus conductance arteries in general, and that what Naderali et al. previously observed (13) was due to some other property that differed between their mesenteric and uterine arterial preparations.

For our second specific aim, we sought to determine if (hypothesis \#2) resveratrol's relaxation of rat tail arterial tissue in vitro could be antagonized by any of the following: tetraethylammonium, iberiotoxin, apamin, glibenclamide, barium, margatoxin and/or 4-aminopyridine; agents known to block different subpopulations of potassium $(\mathrm{K})$ channels in arterial smooth muscle. Channels blocked by these agents are defined under Study 2 (Aim 2) in Methods. Published studies on different arterial vessels isolated from different animals have already found that some of these agents antagonize relaxation by resveratrol while others do not $(12,14-$ 16), suggesting that resveratrol may cause relaxation by opening some but not other types of arterial smooth muscle $\mathrm{K}$ channels and that it varies notably in that regard from one type of artery to another. For example, one previous study on the rat mesenteric artery showed that 4-aminopyridine had a moderate antagonistic effect on resveratrol's relaxation of phenylephrine contraction while glibenclamide, tetraethylammonium, charybdotoxin, margatoxin and barium had no effects (12). Another study on phenylephrine-contracted human mammary arteries reported different results showing that glibenclamide, tetraethylammonium, and charybdotoxin did not block resveratrol's relaxant effect while 4-aminopyridine and margatoxin each completely abolished it 
(15). However, another paper reported that glibenclamide and tetraethylammonium did have an antagonistic effect on resveratrol's relaxation of the norepinephrine-contracted rat abdominal aorta (16). And a study on pressurized porcine retinal arterioles reported that while tetraethylammonium and iberiotoxin antagonized resveratrol's relaxant effect, glibenclamide and 4-aminopyridine did not (14). As discussed under Study 2 (Aim 2) in Methods, we tested all of these agents (except charybdotoxin) in both resistance and conductance segments of the rat tail artery to identify any antagonistic effects on resveratrol's relaxant action. In addition to these agents (as used in the abovementioned published studies) we also tested the effect of apamin, a blocker of small-conductance calcium-activated K channels (26), which was not tested in those studies. To allow room for apamin we omitted charybdotoxin because, of the three known blockers of large- and/or intermediateconductance calcium-activated $\mathrm{K}$ channels (tetraethylammonium, iberiotoxin and charybdotoxin), it was the only one that failed to affect resveratrol's relaxant action in the abovementioned published studies $(12,15)$.

If our results had supported our hypothesis, we would have then studied the role of endothelium in the future. We would have retested only those agents that proved to have an antagonistic effect in the present work but with endothelium removed from the vessels in future studies. This would have been important to determine whether the K channels affected by resveratrol belong to the endothelium or the smooth muscle of the vessel wall. Although not as well understood (in terms of their role), K channels do exist in endothelial cells $(32,33)$ as well as in arterial smooth muscle cells $(26,27)$. But since our results did not support our hypothesis, we will consider other possible mechanisms in the future that may be responsible for resveratrol's relaxation of the rat tail artery, such as again the endothelium (though not focusing on its $\mathrm{K}$ channels) but also smooth muscle voltage-gated calcium channels for which others have already provided initial evidence suggesting they play a partial role in the rat mesenteric artery (12).

\section{Unanticipated findings (relevance)}

While resveratrol's vascular relaxing action has been widely established there are no reports to our knowledge of its potential to act as a contracting substance, at least not in vitro. Unexpectedly, we found that resveratrol caused immediate, transient increases in phenylephrine (PE)-induced (thus adrenergic) contractions in over half of our isolated rat tail arterial ring preparations (Figs. 2, 3 and 7), beginning well before any of its sustained relaxant effects became fully apparent (Figs. 2, 5 and 9). It is possible that others have already observed this enhancement of adrenergic contractility in other arteries in vitro but simply chose to ignore it, thinking it was not relevant in vivo. However, we reasoned that if this phenomenon is not limited to just the ventral tail artery of the rat but occurs systemically (in other arteries as well), then it should be possible to find in vivo evidence of it in the form of transient yet meaningful elevations in systemic arterial pressures immediately after intravenous (as opposed to long-term oral) administration. We searched and found eight publications involving arterial pressure monitoring during intravenous administration of resveratrol (34-41); four in which arterial pressures did not change $(34,36,38,39)$ but three in which it was significantly elevated $(35,37$, 40) and one editorial review in which the therapeutic benefit of such elevation was presented and speculation offered as to why some investigators have seen it while others have not (41).

The three studies in which intravenous resveratrol raised arterial pressures involved different species and different experimental conditions. But all had one thing in common, i.e. abnormally low arterial pressures in the absence of resveratrol $(35,37,40)$; so low that its ability to acutely elevate those pressures was considered an important part of its therapeutic benefit $(35,37,41)$. In one study, resveratrol transiently increased arterial pressures while it was infused intravenously into hypotensive fetal sheep (40). The rise in their mean arterial pressures, from a low of approximately $45 \mathrm{mmHg}$ before resveratrol, peaked at about $10 \mathrm{~min}$ and then disap- 
peared approximately 20 min later. Based on our results, this short duration of approximately 30 min can be readily explained by the fact that the dose of resveratrol (approximately $3 \mathrm{mg} / \mathrm{kg}$ ) was high enough to produce a notably high circulating concentration, as calculated by the authors to be over $100 \mu \mathrm{M}(40)$. As such, this in vivo effect is remarkably consistent with results we observed after direct administration of our high test concentrations of resveratrol to isolated rat tail arterial tissue in vitro. For example, at resveratrol concentrations of 40 and $80 \mu \mathrm{M}$ we observed nearly an identical time course for its ability to transiently enhance PE-induced contractions (Fig. 4). In another study, adult endotoxemic rats were continuously infused with a 10-fold lower dose of resveratrol $(0.3 \mathrm{mg} / \mathrm{kg})$ which only produced a calculated blood concentration of $4.4 \mu \mathrm{M}$ (35). This infusion significantly improved mean arterial pressure recovery in these rats from a low baseline level of 36 $\mathrm{mmHg}$ (as induced by the experimental endotoxemia) and this recovery was much longer in duration (i.e. less transient). It was particularly noteworthy as late as 60-120 min after that induction (35). This in vivo effect is again remarkably consistent with our results but with administration of our lower test concentrations of resveratrol in vitro, as seen for example with $5 \mu \mathrm{M}$ after which enhancement of our PE-induced contractions lasted much longer than after the higher concentrations (Figs. 2 and 4). Finally, in the third study (37), an even lower intravenous dose of resveratrol $(0.1 \mathrm{mg} / \mathrm{kg})$ raised even lower baseline levels of mean arterial pressures than those seen in the above two studies $(35,40)$. These particularly low arterial pressures were caused by infrarenal aortic clamping designed to experimentally induce traumatic ischemic spinal cord injury in adult rabbits. Resveratrol's ability to correct them was seen both proximal and distal to the site of aortic clamping and considered by both the authors (37) and an editorial reviewer of the study (41) to be potentially as important as its known antioxidant action, in terms of the protection it afforded against permanent spinal cord damage. Authors of this third study (and the remaining studies discussed below) did not report blood concentrations for resveratrol.

None of the authors of these three in vivo studies $(35,37,40)$ nor the editorial reviewer (41) commented on the mechanism responsible for resveratrol's ability to acutely elevate arterial pressure during its intravenous administration. Our in vitro work now offers a reasonable explanation for it, i.e. enhancement of the whole body's adrenergic vasoconstrictor support of arterial pressure in vivo by way of a direct enhancing action on adrenergic contraction of arterial vessels, as we observed in vitro in one such vessel.

But why did intravenous resveratrol only increase arterial pressures in some studies $(35,37,40)$ and not in others $(34,36,38,39)$ ? The most obvious answer is if the doses were simply too low to do so. And that may have been the case in at least one of them in which extremely low intravenous doses (at and below $0.001 \mathrm{mg} /$ $\mathrm{kg}$ ) failed to acutely increase (or decrease) mean arterial pressures in rats with experimentally-induced cerebral ischemia (36). Admittedly, their baseline pressures were already elevated in the absence of resveratrol and in need of no further elevation. But more importantly, such extremely low doses may not be able to produce circulating concentrations of resveratrol capable of enhancing (or inhibiting) adrenergic support of arterial vasoconstriction and related arterial pressure. However, it is also possible that there may be doses of resveratrol which are paradoxically too high to acutely increase arterial pressures during intravenous administration. The abovementioned editorial reviewer (41) raised this issue when comparing two different studies from two different laboratories treating the same condition (ischemia-reperfusion-induced spinal cord injury) in the same species (adult New Zealand white rabbits), but with a large difference in intravenous dose, i.e. $0.1 \mathrm{mg} / \mathrm{kg} \mathrm{which}$ increased arterial pressure in the one study as already mentioned (37), and $1 \mathrm{mg} / \mathrm{kg}$ and $10 \mathrm{mg} / \mathrm{kg}$ neither of which increased arterial pressure in the other study (38). In our opinion, the latter might be explained as follows. At high enough intravenous doses (e.g. the $10 \mathrm{mg} / \mathrm{kg}$ dose) the duration of any acute increase in blood pressure might not last long enough to be detected. We think this can simply be extrapolated from the already 
abovementioned notably shorter duration of increased arterial pressure in the fetal sheep given $3 \mathrm{mg} / \mathrm{kg}$ (40) compared to the endotoxemic rats given only $0.3 \mathrm{mg} / \mathrm{kg}$ in vivo (35). We could also extrapolate it from our own in vitro observation of decreasing durations in time for the transient enhancements of adrenergic contractions caused by resveratrol as we progressively increased its concentration from lower to higher levels (Fig. 4).

But that still leaves the $1 \mathrm{mg} / \mathrm{kg}$ dose given to the rabbits $(38)$ plus two other rat studies $(34,39)$ in which intravenous resveratrol failed to increase arterial pressures even though administered within the range of doses that did increase pressures in the first three studies mentioned above $(35,37,40)$. Thus, for these studies (and perhaps for all the abovementioned studies) there may be factors other than dose which are important in determining whether or not intravenous resveratrol increases blood pressure. Such factors could be similar to those which determine why some of our in vitro tissues do and some do not show transient increases in adrenergic contractions in response to resveratrol. Accordingly, more in vitro experiments with our isolated tail artery preparations designed to uncover these factors may shed light on better use of intravenous resveratrol in the future, especially in animal models (and patients) in which severe hypotension (in need of correction) accompanies traumatic ischemic tissue injury. One of several factors that we intend to study in the future is the composition of our physiological buffer, focusing especially on levels of glucose, electrolytes, oxygen, carbon dioxide and $\mathrm{pH}$. Measuring these factors in blood samples was considered important in most of the abovementioned in vivo studies in which resveratrol was given intravenously to whole animals $(35-37,39,40)$; many with experimentally-induced ischemic tissue injury $(35-37,39)$. In fact, marked and distinctly different changes in a number of these factors (due to the injuries) were reported in two of these studies, one in which intravenous resveratrol increased arterial pressure (35) and one in which it did not (39).

\section{Unanticipated findings (mechanisms)}

We were not able to identify the precise mechanism whereby resveratrol enhanced adrenergic contractions in our tail artery tissues but we did identify agents with which to further study it in the future. We found that at least two of the seven $\mathrm{K}$ channel blocking agents we employed in aim \#2 above, TEA and glibenclamide, notably inhibited both the magnitude and duration of the transient increases in PE-induced contractions caused by resveratrol (Figs. 7 and 8). This would lead one to suspect that TEA-sensitive and glibenclamide-sensitive $\mathrm{K}$ channels might play a role in the mechanism involved. However, because of the well-known relaxing role of these and other $\mathrm{K}$ channels in smooth muscle, it is generally thought that $\mathrm{K}$ channel blockers only block smooth muscle responses to relaxing and not contracting substances $(26,27)$. Thus, we considered that when TEA and glibenclamide inhibited the transient contractions caused by resveratrol they were working at a site other than smooth muscle; either the adjacent endothelium and/or sympathetic nerve endings. Both are capable of releasing contracting substances onto the smooth muscle and resveratrol could potentially cause such release even if only transiently; e.g. norepinephrine from sympathetic nerve endings and endothelin-1 from the endothelium. However, TEA is already known to facilitate, not inhibit, norepinephrine release from electrically-stimulated sympathetic neurons (42). Therefore, although we do not entirely rule them out, this would argue against the role of nerve endings in our results with TEA because it inhibited rather than facilitate the transient resveratrol-induced contractions that we observed. We think the more likely possibility is that TEA (and perhaps glibenclamide as well) may be blocking transient resveratrol-induced release of contracting factors from the endothelium.

Less is known about the role of endothelial $\mathrm{K}$ channels in endothelial release of contracting factors compared to relaxing factors $(32,33)$. However, it is known that vascular endothelial cells possess mechanosensitive ion channels which when stretched can directly alter the release of endothelial contracting factors 
(as well as relaxing factors) or indirectly alter the ability of various endogenous agonists like acetylcholine to release contracting factors $(32,33,43-45)$. There are at least two reasons why we suspect that resveratrol may be acting as such an agonist; or more specifically, acting on such mechano-sensitive ion channels in the endothelium. First, some of those channels are known to be K-selective (33) and therefore potential sites for a K-channel related action of resveratrol that could conceivably be blocked by K channel blockers. Second, some of the endothelium-dependent contractions which have been observed in response to excess stretch of the wall of some arteries have been reported as transient in duration $(44,46)$, thus similar in that respect to what we observed with resveratrol. Studies of the effects of deliberate arterial wall stretch on release of endothelial contracting factors have been conducted with experimentally-induced changes in both passive loading (resting) tensions as applied to isolated arterial rings (43-46) and perfusion pressures as applied to isolated but whole cannulated arteries (47). Either way yields essentially the same results, i.e. excess stretch when deliberately applied can not only impair arterial endothelium-dependent relaxations (including acetylcholine-induced) (43) but also promote release of endothelium contracting factors $(43,44,46)$ and stimulate endothelial production of reactive oxygen species (48) which in turn can contribute to endothelium-dependent contractile responses to acetylcholine (45). Thus, in future experiments we will obviously test whether resveratrol's contractionenhancing action is dependent on intact endothelium. If it is, we will then determine if experimentally adjusting passive loading (resting) tensions up or down prior to administration of resveratrol can alter how many tissue rings respond to its transient contracting effect; and possibly even alter the magnitude and duration of those responses.

Finally, it is possible that the ability of glibenclamide in particular to inhibit resveratrol's contractionenhancing action may not involve the endothelium (or even K channels) at all. Glibenclamide has been reported to inhibit contractions produced by prostaglandin F2 $\alpha$ in rings prepared from rat aorta and canine femoral, mesenteric, renal, coronary and cerebral arteries (49). This inhibition was not dependent on the presence of intact endothelium (49). The authors concluded that glibenclamide was acting specifically at the level of the arterial smooth muscle receptor for only prostaglandin F2 $\alpha$ and/or its intracellular smooth muscle signal transduction pathway, but not on glibenclamide-sensitive K channels within the smooth muscle cell membrane (49). We will conduct future studies to determine if glibenclamide (and perhaps TEA as well) is acting similarly to inhibit the contraction-enhancing action of resveratrol, possibly at a yet to be identified polyphenol receptor site on smooth muscle that specifically binds resveratrol.

\section{Acknowledgments}

The authors wish to thank the Biomedical Sciences Program of Midwestern University for funding this project. The authors also wish to acknowledge the assistance of Victoria Sears and Sarah Schmidt in the preparation of the manuscript and Joseph T. Pasquesi Jr. for improving flow and visibility of bath water required to warm our individual tissue baths.

\section{Conflict of interest}

The authors declare they have no conflict of interest. 


\section{References}

1. Belguendouz L, Fremont L, Linard A. Resveratrol inhibits metal ion-dependent and independent peroxidation of porcine low-density lipoproteins. Biochem Pharmacol. 1997; 53(9): 1347-55. PubMed PMID: 9214696.

2. Bhatt JK, Thomas S, Nanjan MJ. Resveratrol supplementation improves glycemic control in type 2 diabetes mellitus. Nutri Res (New York, NY). 2012; 32(7): 537-41. PubMed PMID: 22901562.

3. Brown VA, Patel KR, Viskaduraki M, Crowell JA, Perloff M, Booth TD, Vasilinin G, Sen A, Schinas AM, Piccirilli G, Brown K, Steward WP, Gescher AJ, Brenner DE. Repeat dose study of the cancer chemopreventive agent resveratrol in healthy volunteers: safety, pharmacokinetics, and effect on the insulin-like growth factor axis. Cancer Res. 2010; 70(22): 9003-11. PubMed PMID: 20935227.

4. Chan V, Fenning A, Iyer A, Hoey A, Brown L. Resveratrol improves cardiovascular function in DOCAsalt hypertensive rats. Curr Pharm Biotechnol. 2011; 12(3): 429-36. PubMed PMID: 20874677.

5. Dolinsky VW, Chakrabarti S, Pereira TJ, Oka T, Levasseur J, Beker D, Zordoky BN, Morton JS, Nagendran J, Lopaschuk GD, Davidge ST, Dyck JR. Resveratrol prevents hypertension and cardiac hypertrophy in hypertensive rats and mice. Biochim Biophys Acta. 2013; 1832(10): 1723-33. PubMed PMID: 23707558.

6. Iervasi G, Forini F, Sabatino L. A glass of wine: how good is good? The resveratrol lesson*. Crit Care Med. 40. 2012. p. 3098-9. PMID: 23080448

7. Liu Z, Song Y, Zhang X, Zhang W, Mao W, Wang W, Cui W, Jia X, Li N, Han C, Liu C. Effects of transresveratrol on hypertension-induced cardiac hypertrophy using the partially nephrectomized rat model. Clin Exp Pharmacol Physiol. 2005; 32(12): 1049-54. PubMed PMID: 16445570.

8. Patel KR, Scott E, Brown VA, Gescher AJ, Steward WP, Brown K. Clinical trials of resveratrol. Annals of the New York Academy of Sciences. 2011;1215:161-9. PubMed PMID: 21261655.

9. Rivera L, Moron R, Zarzuelo A, Galisteo M. Long-term resveratrol administration reduces metabolic disturbances and lowers blood pressure in obese Zucker rats. Biochem Pharmacol. 2009; 77(6): 1053-63. PubMed PMID: 19100718.

10. Timmers S, Konings E, Bilet L, Houtkooper RH, van de Weijer T, Goossens GH, Hoeks J, van der Krieken S, Ryu D, Kersten S, Moonen-Kornips E, Hesselink MK, Kunz I, Schrauwen-Hinderling VB, Blaak EE, Auwerx J, Schrauwen P. Calorie restriction-like effects of 30 days of resveratrol supplementation on energy metabolism and metabolic profile in obese humans. Cell Metab. 2011; 14(5): 612-22. PubMed PMID: 22055504

11. Toklu HZ, Sehirli O, Ersahin M, Suleymanoglu S, Yiginer O, Emekli-Alturfan E, Yarat A, Yegen BC, Sener G. Resveratrol improves cardiovascular function and reduces oxidative organ damage in the renal, cardiovascular and cerebral tissues of two-kidney, one-clip hypertensive rats. J Pharm Pharmacol. 2010; 62(12): 1784-93. PubMed PMID: 21054406.

12. Gojkovic-Bukarica L, Novakovic A, Kanjuh V, Bumbasirevic M, Lesic A, Heinle H. A role of ion channels in the endothelium-independent relaxation of rat mesenteric artery induced by resveratrol. J Pharm Sci. 2008; 108(1): 124-30. PubMed PMID: 18818483.

13. Naderali EK, Doyle PJ, Williams G. Resveratrol induces vasorelaxation of mesenteric and uterine arteries from female guinea-pigs. Clin Sci. 2000; 98(5): 537-43. PubMed PMID: 10781384.

14. Nagaoka T, Hein TW, Yoshida A, Kuo L. Resveratrol, a component of red wine, elicits dilation of isolated porcine retinal arterioles: role of nitric oxide and potassium channels. Invest Ophthal Vis Sci. 2007; 48(9): 4232-9. PubMed PMID: 17724212.

15. Novakovic A, Gojkovic-Bukarica L, Peric M, Nezic D, Djukanovic B, Markovic-Lipkovski J, Heinle H. The mechanism of endothelium-independent relaxation induced by the wine polyphenol resveratrol in human internal mammary artery. J Pharm Sci. 2006; 101(1): 85-90. PubMed PMID: 16682785. 
16. Shen M, Zhao L, Wu RX, Yue SQ, Pei JM. The vasorelaxing effect of resveratrol on abdominal aorta from rats and its underlying mechanisms. Vascul Pharmacol. 2013; 58(1-2): 64-70. PubMed PMID: 22820258.

17. Medgett IC. alpha 2-Adrenoceptors mediate sympathetic vasoconstriction in distal segments of rat tail artery. Eur J Pharmacol. 1985; 108(3): 281-7. PubMed PMID: 2859211.

18. Rajanayagam MA, Medgett IC. Greater activation of smooth muscle alpha-2 adrenoceptors by epinephrine in distal than in proximal segments of rat tail artery. J Pharmacol Exp Ther. 1987; 240(3): 989-97. PubMed PMID: 3031281.

19. Souza FM, Padilha AS, Stefanon I, Vassallo DV. Differences in functional and structural properties of segments of the rat tail artery. Braz J Med Biol Res. 2008; 41(5): 416-23. PubMed PMID: 18516469.

20. Peuler JD, Lee JM, Smith JM. 4-Aminopyridine antagonizes the acute relaxant action of metformin on adrenergic contraction in the ventral tail artery of the rat. Life Sci. 1999; 65(23): P1 287-93. PubMed PMID: 10622240.

21. Peuler JD, Warfield RK, Phelps LE. Attenuation by 4-aminopyridine of delayed vasorelaxation by troglitazone. Metabolism. 2004; 53(2): 147-52. PubMed PMID: 14767864.

22. Peuler JD, Phelps LE. Sildenafil does not enhance but rather attenuates vasorelaxant effects of antidiabetic agents. J Smooth Muscle Res. 2015; 51: 22-36. PubMed PMID: 26004378.

23. Phelps LE, Peuler JD. Evidence of direct smooth muscle relaxant effects of the fibrate gemfibrozil. J Smooth Muscle Res. 2010; 46(3): 125-42. PubMed PMID: 20647690.

24. Stanke-Labesque F, Cracowski JL, Devillier P, Caron F, Bessard G. Functional assessment of rat aorta after cold storage in different media. Fundam Clin Pharmacol. 1999; 13(3): 310-9. PubMed PMID: 10392307.

25. Peuler JD, Scotti MA, Phelps LE, McNeal N, Grippo AJ. Chronic social isolation in the prairie vole induces endothelial dysfunction: implications for depression and cardiovascular disease. Physiol Behav. 2012 Jun 25; 106(4): 476-84. PubMed PMID: 22469565.

26. Brayden JE. Potassium channels in vascular smooth muscle. Clin Exp Pharmacol Physiol. 1996; 23(12): 1069-76. PubMed PMID: 8977162.

27. Nelson MT, Quayle JM. Physiological roles and properties of potassium channels in arterial smooth muscle. Am J Physiol. 1995; 268(4 Pt 1): C799-822. PubMed PMID: 7733230.

28. Rembold CM, Chen XL. Mechanisms responsible for forskolin-induced relaxation of rat tail artery. Hypertension. 1998; 31(3): 872-7. PubMed PMID: 9495275.

29. Halpern W, Osol G. Resistance vessels in hypertension. Progress in Clinical and Biological Research. 1986; 219: 211-23. PubMed PMID: 3538026.

30. Luksha L, Agewall S, Kublickiene K. Endothelium-derived hyperpolarizing factor in vascular physiology and cardiovascular disease. Atherosclerosis. 2009; 202(2): 330-44. PubMed PMID: 18656197.

31. Woodman OL, Wongsawatkul O, Sobey CG. Contribution of nitric oxide, cyclic GMP and K+ channels to acetylcholine-induced dilatation of rat conduit and resistance arteries. Clin Exp Pharmacol Physiol. 2000; 27(1-2): 34-40. PubMed PMID: 10696526.

32. Nilius B, Viana F, Droogmans G. Ion channels in vascular endothelium. Annual Review Of Physiology. 1997; 59: 145-70. PubMed PMID: 9074759.

33. Nilius B, Droogmans G. Ion channels and their functional role in vascular endothelium. Physiol Rev. 2001 Oct; 81(4): 1415-59. Review. PubMed PMID: 11581493.

34. Gordish KL, Beierwaltes WH. Resveratrol induces acute endothelium-dependent renal vasodilation mediated through nitric oxide and reactive oxygen species scavenging. Am J Physiol Renal Physiol. 2014 Mar 1; 306(5): F542-50. PubMed PMID: 24431202.

35. Hamburger T, Broecker-Preuss M, Hartmann M, Schade FU, de Groot H, Petrat F. Effects of glycine, pyruvate, resveratrol, and nitrite on tissue injury and cytokine response in endotoxemic rats. J Surg Res. 
2013 Jul; 183(1): e7-e21. PubMed PMID: 23434211.

36. Huang SS, Tsai MC, Chih CL, Hung LM, Tsai SK. Resveratrol reduction of infarct size in Long-Evans rats subjected to focal cerebral ischemia. Life Sci. 2001 Jul 20; 69(9): 1057-65. PubMed PMID: 11508648 .

37. Kaplan S, Bisleri G, Morgan JA, Cheema FH, Oz MC. Resveratrol, a natural red wine polyphenol, reduces ischemia-reperfusion-induced spinal cord injury. Ann Thorac Surg. 2005 Dec; 80(6): 2242-9. PubMed PMID: 16305881.

38. Kiziltepe U, Turan NN, Han U, Ulus AT, Akar F. Resveratrol, a red wine polyphenol, protects spinal cord from ischemia-reperfusion injury. J Vasc Surg. 2004 Jul; 40(1): 138-45. PubMed PMID: 15218474.

39. Petrat F, de Groot H. Protection against severe intestinal ischemia/reperfusion injury in rats by intravenous resveratrol. J Surg Res. 2011 May 15; 167(2): e145-55. PubMed PMID: 20850780.

40. Reimsnider SK, Wood CE. Does reduction of circulating prostaglandin E2 reduce fetal hypothalamicpituitary-adrenal axis activity? J Soc Gynecol Investig. 2005; 12(4): e13-9. PubMed PMID: 15866108.

41. Toumpoulis IK. Resveratrol or higher arterial blood pressure protects the spinal cord from ischemiareperfusion injury? Ann Thorac Surg. 2006 Oct; 82(4): 1572-3. PubMed PMID: 16996993.

42. Przywara DA, Mashalkar V, Bhave SV, Wakade TD, Wakade AR. Tetraethylammonium facilitation of single-pulse mediated action potential, $[\mathrm{Ca} 2+] \mathrm{i}$ and transmitter release in sympathetic neurons. Eur J Pharmacol. 1993; 247(3): 353-6. PubMed PMID: 7905832.

43. Sekiguchi F, Adachi T, Matsubara H, Matsuda K, Kita K, Shimamura K, Sunano S. Spontaneous and agonist-induced contractions and endothelium-dependent relaxation in aortae from SHRSP and WKY rats under various levels of passive force. Clin Exp Pharmacol Physiol. 1996 Jun-Jul; 23(6-7): 483-9. PubMed PMID: 8800570.

44. Vanhoutte PM. Endothelium-dependent contractions in arteries and veins. Blood Vessels. 1987; 24(3): 141-4. PubMed PMID: 3109528.

45. Yang D, Félétou M, Boulanger CM, Wu HF, Levens N, Zhang JN, Vanhoutte PM. Oxygen-derived free radicals mediate endothelium-dependent contractions to acetylcholine in aortas from spontaneously hypertensive rats. Br J Pharmacol. 2002 May; 136(1): 104-10. PubMed PMID: 11976274.

46. Katusic ZS, Shepherd JT, Vanhoutte PM. Endothelium-dependent contraction to stretch in canine basilar arteries. Am J Physiol. 1987 Mar; 252(3 Pt 2): H671-3. PubMed PMID: 3103472.

47. Harder DR. Pressure-induced myogenic activation of cat cerebral arteries is dependent on intact endothelium. Circ Res. 1987 Jan; 60(1): 102-7. PubMed PMID: 3568282.

48. Hishikawa K, Lüscher TF. Pulsatile stretch stimulates superoxide production in human aortic endothelial cells. Circulation. 1997 Nov 18; 96(10): 3610-6. PubMed PMID: 9396462.

49. Zhang H, Stockbridge N, Weir B, Krueger C, Cook D. Glibenclamide relaxes vascular smooth muscle constriction produced by prostaglandin F2 alpha. Eur J Pharmacol. 1991 Mar 19; 195(1): 27-35. PubMed PMID: 1906005. 